\title{
Research and Application of Information Management of Quality Inspection Data in Bridge Construction
}

\author{
X X Wang ${ }^{1}$, J D Zhang ${ }^{1}$ \\ ${ }^{1}$ Key Laboratory for Bridge and Tunnel of Shannxi Province, Chang'an University Xi'an, PR China
}

\begin{abstract}
Highway engineering quality inspection and evaluation is a key link in highway engineering construction project quality control, and efficient and effective is essential to quality inspection and evaluation. Combined with the quality inspection and assessment standards, a standardized standard library was formed, and the engineering division was improved to achieve refined engineering division and rationalized engineering division. Through the quality assessment and quality rectification, the whole process of assessment is completed, and the QR code visualization technology is used to match the quality inspection table to realize the information management of the quality inspection data and complete the system research and development. Finally, according to the specific engineering application, the efficiency of bridge engineering quality inspection and evaluation is improved, the evaluation data is effectively managed, and the system functions are fully verified.
\end{abstract}

\section{Introduction}

Highway engineering quality inspection and evaluation is the key link of highway engineering construction project quality control. Efficient and effective implementation of quality inspection and evaluation can strictly control the construction quality of highway projects and promote the management of bridge construction projects. Therefore, the quality inspection and evaluation is regarded as an important indicator of integrated management in the bridge information construction system.

Since the 21 st century, the government and related units have continuously promoted the level of informatization application and issued relevant policy documents. The 18th National Congress of the Communist Party of China emphasized the need to comprehensively improve the informatization level of the construction industry during the 13th Five-Year this reflects the country's clear attitude towards the development of informatization in the construction field ${ }^{[1]}$. In daily work, the owner unit, construction unit, supervision unit, etc. must record a large amount of actual measurement data, fill in and manage a large number of self-inspection forms, random inspection.

A large number of repetitive and tedious manual operations increase labour intensity, and it is difficult to ensure the scientific nature of the data. In particular, the traceability of the data logic between the various files mentioned above has increased the complexity and workload of data aggregation. Early testing and detection, as well as the processing and summary of actual measurement data are not timely, which usually results in imperfect basic data for sub-project evaluation. Therefore, it is necessary to use information technology to transform the on-site quality assessment model of complex circulation into an online multi-agent model.

\section{Quality Inspection and Evaluation Methods of Bridge Engineering}

\subsection{Current Bridge Engineering Quality Inspection and Evaluation Methods}

"Highway Engineering Quality Inspection and Evaluation Standard Volume One Civil Engineering [S]. JTG F80/1 - 2017"(Abbreviated as "JTG F80/1-2017") was officially released in December 2017. This marks the 13year-old version of "Highway Engineering Quality Inspection and Evaluation Standard Volume One Civil Engineering [S]. JTG F80/1-2004" (hereinafter referred to as "JTG F80/1-2004") to stop using ${ }^{[2]}$. The newly promulgated standards make the following provisions.

Basic requirements assessment. The basic requirements assessment has the right to veto the project quality assessment, and all requirements must meet the standard requirements. The basic requirements of the item projects shall be inspected item by item, and quality assessment cannot be conducted if there is any noncompliance with the specified requirements.

Evaluation of measured items. The selection of test points for inspection items must be randomly sampled according to the prescribed inspection methods and inspection frequencies, and the qualification rate method shall be used for quality assessment. The qualified rate of inspection items is calculated as follows: 


$$
\text { project qualification rate }=\frac{\text { qualified points }}{\text { All points }} \times 100 \%
$$

The inspection items are divided into general items and key items. The pass rates of general items and key items are different, and the key items are more stringent. As shown in Table 1. In addition, there are inspection items with prescribed extreme values. As long as the value of any one of the measuring points exceeds this value, it is judged as unqualified.

Appearance quality and quality assurance data assessment. The new standard is very rigid for the quality assessment of appearance quality and quality assurance information. The appearance quality must meet the specified requirements, otherwise it will be assessed as unqualified and the subsequent quality assessment cannot be carried out; the quality assurance information must be complete, otherwise it will be assessed as unqualified.

\subsection{Comparison of quality assessment methods}

\begin{tabular}{|c|c|}
\hline 《JTG F80/1-2004》 & 《JTG F80/1-2017》 \\
\hline Percentile scoring & Qualified Rate Method \\
\hline $\begin{array}{l}\text { Carry out a comprehensive inspection of the } \\
\text { appearance of the project item by item, and deduct } \\
\text { points for non-compliance with the standard } \\
\text { requirements. }\end{array}$ & $\begin{array}{l}\text { A comprehensive inspection of the } \\
\text { appearance is carried out, and those that do not } \\
\text { meet the requirements of the standard are } \\
\text { judged as unqualified and cannot be quality } \\
\text { assessed. }\end{array}$ \\
\hline $\begin{array}{l}\text { The construction data and diagrams should be } \\
\text { complete. Those who lack basic data or are forged } \\
\text { or altered cannot conduct quality assessment. If } \\
\text { the data is incomplete, points should be reduced. }\end{array}$ & $\begin{array}{l}\text { The quality assurance information in the } \\
\text { project should be true, accurate, complete. }\end{array}$ \\
\hline $\begin{array}{l}\text { Item project score }=\text { item project score-deduction } \\
\text { for appearance defects-deduction for incomplete } \\
\text { data. Item project score } \geqslant 75 \text { points, it is } \\
\text { qualified; }<75 \text { points, it is unqualified; mechanical } \\
\text { and electrical engineering, factory processed } \\
\text { metal components } \geqslant 90 \text { points, it is qualified. }\end{array}$ & $\begin{array}{l}\text { The pass rate of key items is } \geqslant 95 \% \text {, and the } \\
\text { pass rate of general items is } \geqslant 80 \% \text {; for } \\
\text { inspection items with prescribed extreme } \\
\text { values, as long as the value of any one of the } \\
\text { measuring points exceeds this value, it will } \\
\text { be judged as unqualified. }\end{array}$ \\
\hline
\end{tabular}

\subsection{Refined engineering division}

\subsubsection{Insufficiency of engineering division in current standards.}

Engineering division needs to be flexible in application. Relying on standardized engineering division cannot fit well with engineering application. The evaluation level of the new version of "Highway Engineering Quality Inspection and Evaluation Standard Civil Engineering" is: project $\rightarrow$ contract section $\rightarrow$ single project $\rightarrow$ subproject $\rightarrow$ item project $\rightarrow$ inspection item (basic
In terms of project division, both the old and new versions take single project, subproject, and item project as a main line, which is still the basis for quality inspection and evaluation. In the evaluation algorithm, "JTG F80/12017" appears to be more direct and simple. The weighted average method of "JTG F80/1-2004" is eliminated, and the pass rate algorithm is used to determine whether it is qualified or not, which is simple and effective. The procedure improves the efficiency of quality assessment and facilitates the integrated management of bridge information construction. In the appearance quality and quality assurance materials, the new standard is more rigid to judge through the prescribed standards, instead of using the defect deduction method like the old standard. This improves the evaluation standards and facilitates on-site evaluation management and data acquisition in the bridge construction process.

Table1. Comparison of quality inspection and evaluation standards ${ }^{[3,4]}$ 
Standard Civil Engineering", it cannot be specific to a specific part of the bridge engineering entity, and it cannot reflect the complexity of the on-site bridge engineering construction Happening. Therefore, it is necessary to introduce the concepts of sub-divisional subproject and sub-divisional item project, and combine it with the division of bridge components in the assessment of bridge technical condition to carry out refined engineering division.

\subsubsection{Refined engineering division.}

In the engineering division of bridge engineering foundation and substructure, because there will be multiple piers and abutments in the bridge engineering, the scope concept of sub-division subproject can be introduced, such as "1\# pier foundation and substructure", It is defined that all item projects under this sub-project belong to the scope of Pier 1\#.

The sub-project should be at the component level in the classification of bridge components, such as bored piles, etc. Of course, the quality evaluation during the bridge construction process is not to evaluate the entire components, but to evaluate based on the construction process, such as the construction of piers and abutments. Quality inspection and evaluation should be carried out in accordance with the specified unit length. Therefore, by introducing the sub-division item project and naming them according to the construction requirements, such as "pier and abutment body installation_first section (0-5m)", you can know the location of the quality assessment work in the bridge structure more clearly, which is convenient for management and at the same time provides a data foundation for the visualization requirements of subsequent bridge informatization construction.

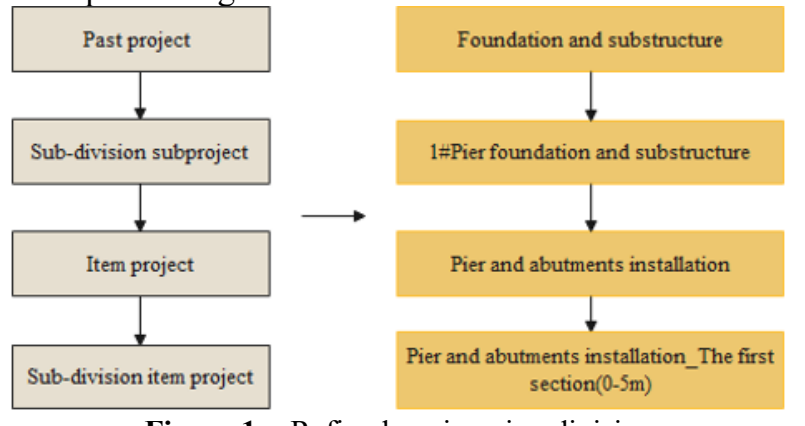

Figure 1. Refined engineering division

\section{Information Management of Bridge Engineering Quality Inspection and Evaluation}

Regarding quality inspection and evaluation, many systems have been developed in recent years, but most of the systems have (1) The standardized process of quality inspection and evaluation is fragmented, and can only meet the requirements of specific project completion document forms, which is poor in adaptability; (2) Only positioned on computer-aided calculation, ignoring the important role of quality inspection data management ${ }^{[5]}$. It is of great significance to develop a scientific, complete, adaptable, and highly automated quality inspection and evaluation system based on the current norms.

\subsection{Standardized and rationalized assessment process}

Based on "Highway Engineering Quality Inspection and Evaluation Standard Civil Engineering", develop the quality management module, benchmarking engineering application, improve the evaluation process, and refine the project division. Due to the particularity of its evaluation in the project, add the function of custom evaluation template, add the evaluation items that do not exist in the specification, to improve the evaluation content, solve the engineering needs. Combining the two aspects of quality assessment and quality rectification, the bridge engineering quality inspection and assessment are standardized and rationalized. The assessment process is shown in Figure 2.

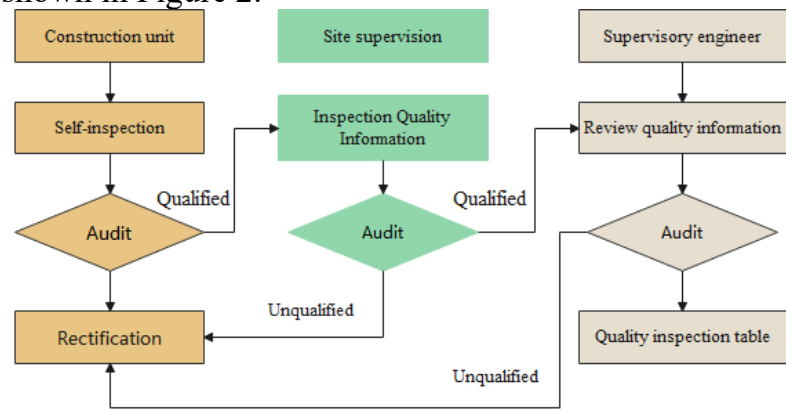

Figure 2. Bridge construction quality inspection system assessment process

\subsection{Quality inspection data management}

\subsubsection{QR code technology}

With the orderly advancement of engineering information construction, QR code technology has continued to be popularized, and now it is gradually integrated with the construction field ${ }^{[6]}$. Two-dimensional codes can be divided into two-dimensional barcodes and matrix twodimensional codes. The matrix QR code is used in this system. Compared with other types of two-dimensional codes, QR codes have the characteristics of fast recognition speed, large amount of data, and small resource consumption. In the QR code, the different twodimensional positions of the black and white blocks determine the meaning of the two-dimensional code. Encode the black and white blocks at different positions in the matrix, and complete the reading and analysis of the QR code content by the computer through the steps of barcode positioning, barcode segmentation, and decoding ${ }^{[7]}$. Table 2 shows the comparison of twodimensional bar code and matrix two-dimensional code. 
Table2. Comparison of two-dimensional bar code and matrix two-dimensional code

\begin{tabular}{|c|c|c|}
\hline Compare items & barcodes & matrix QR code \\
\hline $\begin{array}{l}\text { Amount of stored } \\
\text { information }\end{array}$ & Less information & More information \\
\hline Space usage & $\begin{array}{l}\text { Information is stored in one } \\
\text { direction, and the same amount } \\
\text { of information occupies a larger } \\
\text { physical location }\end{array}$ & $\begin{array}{l}\text { Store information in both } \\
\text { horizontal and vertical directions, } \\
\text { the same amount of information } \\
\text { occupies about one-tenth of the } \\
\text { space of a two-dimensional } \\
\text { barcode }\end{array}$ \\
\hline $\begin{array}{l}\text { Environmental } \\
\text { adaptability }\end{array}$ & $\begin{array}{l}\text { Does not have its own "error } \\
\text { correction ability" }\end{array}$ & $\begin{array}{l}\text { With its own "error correction } \\
\text { capability", even if part of the } \\
\text { code is damaged, the data can be } \\
\text { restored appropriately. }\end{array}$ \\
\hline $\begin{array}{l}\text { Information reading } \\
\text { ability }\end{array}$ & $\begin{array}{l}\text { Less positioning information, } \\
\text { easy to be restricted by } \\
\text { background conditions }\end{array}$ & $\begin{array}{l}\text { With } 3 \text { positioning patterns, it is } \\
\text { not easily affected by background } \\
\text { conditions, and the information is } \\
\text { read quickly and stably }\end{array}$ \\
\hline
\end{tabular}

\subsubsection{The application of two-dimensional code in quality assessment}

This system uses the method of linking information to enter the content, taking the design of the QR code generation of the quality inspection evaluation form as an example to introduce.

After establishing a bridge construction project, a complete project division must be completed, and each sub-division item project in the current construction process must be determined. Then the quality inspection information is generated by on-site input through the mobile WeChat applet, and the evaluation process based on the "Highway Engineering Quality Inspection and Evaluation Standards" is completed in the system. Finally, it is submitted level by level. After the on-site supervision and the supervision engineer have completed the audit, the system will generate the QR code of the sub-project quality inspection and evaluation form. Print and paste the QR code in the corresponding location, and the technician logs in the mobile WeChat applet on the mobile terminal to obtain the URL by scanning the QR code. The quality assessment form of the sub-division item project is bound to the URL, and the quality inspection information can be browsed. When the site encounters an emergency and needs to consult the historical information of the quality inspection, it provides a new idea for the technicians, thus providing a reference for the goal of "one thing, one code" in the construction of bridge engineering.

\section{System applications}

\subsection{Engineering background}

A suspension bridge is a control project of the HechuanBishan-Jiangjin Expressway Project. It crosses the Yangtze River $1.8 \mathrm{~km}$ downstream of Youxi Town, Jiangjin District. The total bridge is 1120 meters. The elevation of the bridge is shown in Figure 3. The main bridge is a single-span suspension bridge with a main span of $760 \mathrm{~m}$; The bridge tower adopts a portal frame structure, and the tower foundation adopts a cap and pile foundation structure.

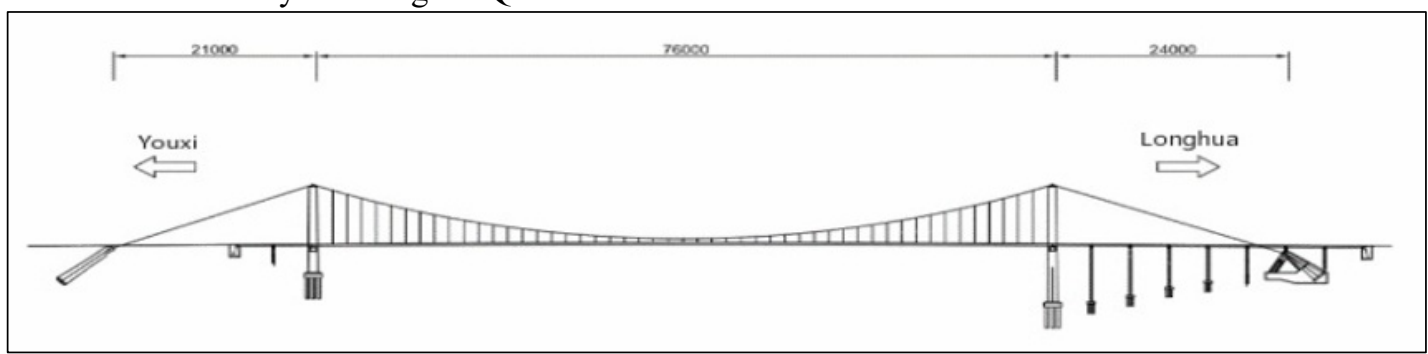

Figure 3. Elevation of the bridge

\subsection{Application of Quality Assessment Information Management}

Based on the research on the refined management of bridge informatization construction, a set of bridge construction quality inspection system with $\mathrm{B} / \mathrm{S}$ architecture was developed based on the .NET platform. The system performs data entry and business transfer on the mobile terminal, and visual display on the web terminal.

\subsubsection{Engineering division}


In the system, the engineering division of suspension bridges is generally divided according to contract sections, single projects, subprojects, and item projects (as shown in Figure 4). Partially combine sub-division single projects, sub-division subprojects, and sub-division item projects for detailed division. The types of bridges used for classification are divided into: general engineering and super large suspension bridges, cable-stayed bridges.

\begin{tabular}{|c|c|c|}
\hline \multicolumn{2}{|l|}{ Add subproject } & tadd \\
\hline${ }^{*}$ Subproject & Please choose & $\hat{\imath}$ \\
\hline $\begin{array}{l}{ }^{*} \text { Subproject code } \\
\text { Subproject description }\end{array}$ & $\begin{array}{l}\text { Foundation and substructure } \\
\text { Superstructure prefabrication and installation } \\
\text { On-site pouring of superstructure } \\
\text { Auxiliary facilities of bridge deck system } \\
\text { Protection engineering }\end{array}$ & \\
\hline Add item project & & tadd \\
\hline${ }^{*}$ Item project & Please choose & $\hat{\wedge}$ \\
\hline $\begin{array}{l}{ }^{*} \text { Item project code } \\
\text { Item project description }\end{array}$ & $\begin{array}{l}\text { Rebar processing and installation } \\
\text { Prestressed tendons processing and tensioning } \\
\text { Grouting and anchoring of prestressed pipeline } \\
\text { Concrete expansion foundation } \\
\text { drilling piles }\end{array}$ & \\
\hline
\end{tabular}

Figure 4. Standardized division

In general engineering, the single project is "suspension bridge approach"; Sub-division single projects of the lower level include "left frame of suspension approach bridge" and "right frame of suspension approach bridge". The division of subprojects is consistent with the specifications, such as "foundation and substructure" etc. The sub-division subproject is divided into "4\# Pier foundation and substructure" in more detail. Item projects are divided based on specifications, such as "rebar processing and installation", Sub-division item projects are divided according to the requirements of inspection and evaluation batches, such as "rebar processing and installation_ first section $(0-1 \mathrm{~m}) "$. The project division is shown in Figure 5.
The engineering division of super suspension bridges and cable-stayed bridges is more detailed. The single project is actually at the same level as the subproject in general engineering, such as "towers and auxiliary, transitional piers", named "suspension bridge $3 \#$ pier foundation and substructure", etc. The division of subprojects, sub-division subprojects, item projects, and sub-division item projects is consistent with the engineering division of the above-mentioned general projects, such as "cable tower", "03\# cable tower", "03\#Processing and installation of steel bar on left pier of cable tower", "03\# Processing and installation of steel bar on left pier of cable tower_first section (0-0.7m)".

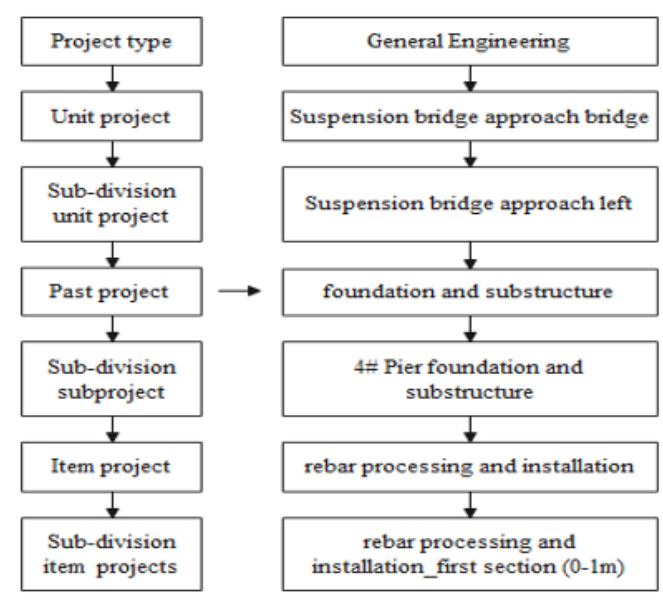

Figure 5. Project division

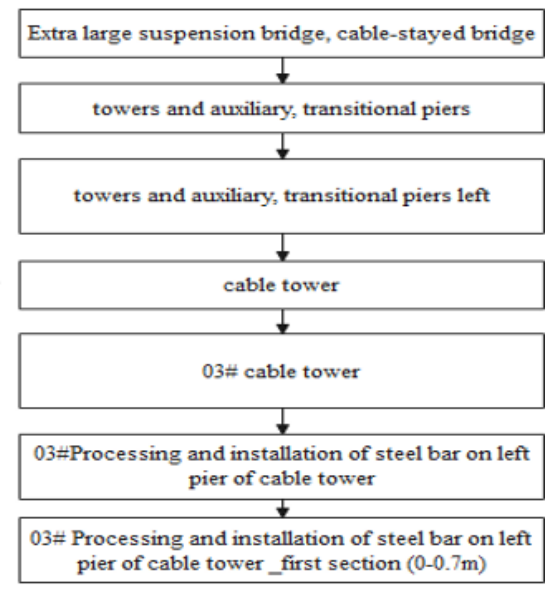

terminal and the mobile WeChat applet, and the two work together to complete the entire quality inspection and evaluation process. The construction quality inspector uses the WeChat applet to fill in the quality inspection data after passing the self-inspection on the spot. During the self-inspection process, if there is a non-conformity, the self-inspection process cannot be completed, and the 
data cannot be submitted. The whole process avoids multiple processing of paper data and improves data validity.

\begin{tabular}{|c|c|c|c|c|c|c|c|c|}
\hline \multicolumn{2}{|c|}{ Quality inspection items } & Status: & Time: & ploosech v & Add & \multirow[t]{2}{*}{ Reset } & View all & \multirow[b]{2}{*}{ operating } \\
\hline Number - & Items o 2 & Measured project o $\checkmark$ & Principal ov & & Status ov $\mathrm{v}$ & & Audit opinion $\vee v$ & \\
\hline 1 & $\begin{array}{l}\text { 3-1mplle roundation } \\
\text { processing and } \\
\text { installation }\end{array}$ & $\begin{array}{l}\text { Measured projects of } \\
\text { bored piles and } \\
\text { diaphragm walls }\end{array}$ & $\begin{array}{l}\text { System } \\
\text { administrator }\end{array}$ & $\begin{array}{l}\text { unavomittrod } \\
\text { Rectification passed } \\
\text { Pesseses }\end{array}$ & - & $\begin{array}{l}\text { (C) } \\
\text { Supervikion } \\
\text { engineet asodit }\end{array}$ & Detsis & View Epport \\
\hline 1 & $\begin{array}{l}\text { 3.2 } 2=\text { Pile foundation } \\
\text { processing and } \\
\text { installation }\end{array}$ & $\begin{array}{l}\text { Measured projects of } \\
\text { bored plles and } \\
\text { oliaphragm walls }\end{array}$ & $\begin{array}{l}\text { System } \\
\text { administrator }\end{array}$ & $\begin{array}{l}\text { submitted } \\
20200507 \\
00: 40\end{array}$ & $\begin{array}{c}\text { Supenision } \\
\text { approved } \\
2020.05-03 \\
11: 15\end{array}$ & $\begin{array}{c}\text { Supenvision } \\
\text { enginer sporowed } \\
2020.09-10 \\
22: 00\end{array}$ & Deasls & View Expor \\
\hline
\end{tabular}

Figure 6. Quality inspection information

\begin{tabular}{|c|c|c|c|c|c|c|c|c|c|c|c|c|c|c|c|}
\hline \multicolumn{16}{|c|}{ Item project quality inspection and evaluation table } \\
\hline \multicolumn{4}{|c|}{ Item project: } & \multicolumn{3}{|c|}{ 3-1\#Pile foundation steel bar proces } & \multicolumn{4}{|c|}{ Subordinate construction project: } & & & & & \\
\hline \multicolumn{4}{|c|}{ subproject: } & \multicolumn{3}{|c|}{\begin{tabular}{|c|c|} 
Tower foundation & \\
\end{tabular}} & \multicolumn{4}{|c|}{ Project of Subsidized Unit: } & & & & & \\
\hline \multicolumn{4}{|c|}{ Construction units } & & & & \multicolumn{4}{|c|}{ Supervision unit: } & & & & & \\
\hline $\begin{array}{l}\text { The basic } \\
\text { requirements }\end{array}$ & \multicolumn{15}{|c|}{$\begin{array}{l}\text { 2.The connection method of the steel bar and the joint area in the same connection section should meet the design requirements; The joint position should be located at a place where } \\
\text { the force is small, and there must be no two joints on the same steel bar in any connecting section. } \\
\text { 3.The lap length, welding and mechanical joint quality of steel bars should meet the requirements of construction technical specifications. } \\
\text { 4.There must be no cracks and other damages on the surface of the stressed steel bar. } \\
\text { 5.The protective layer pads of the steel bars shall be uniformly divided, and the quantity and material properties shall meet the design requirements and relevant technical specifications. }\end{array}$} \\
\hline \multirow{8}{*}{$\begin{array}{l}\text { The measured } \\
\text { project }\end{array}$} & \multirow[b]{2}{*}{ Project } & \multirow[b]{2}{*}{$\begin{array}{c}\text { Check the } \\
\text { project }\end{array}$} & \multirow[b]{2}{*}{ Deviation } & \multirow[b]{2}{*}{$\begin{array}{c}\text { Check the } \\
\text { method }\end{array}$} & \multicolumn{6}{|c|}{ Measured value or measured deviation value } & & & \multicolumn{3}{|c|}{ Quality evaluation } \\
\hline & & & & & 1 & 2 & 3 & 4 & 5 & 6 & 7 & 8 & Average & $\begin{array}{c}\text { Percent of } \\
\text { pass }\end{array}$ & $\begin{array}{l}\text { Conformity } \\
\text { assessment }\end{array}$ \\
\hline & & & & & & & & & & & & & & & \\
\hline & & & & & & & & & & & & & & & \\
\hline & & & & & & & & & & & & & & & \\
\hline & & & & & & & & & & & & & & & \\
\hline & & & & & & & & & & & & & & & \\
\hline & & & & & & & & & & & & & & & \\
\hline \multirow{2}{*}{$\begin{array}{l}\text { Appearance } \\
\text { identification }\end{array}$} & \multirow{2}{*}{\multicolumn{10}{|c|}{$\begin{array}{l}\text { 1. The surface of the steel bars should be free from cracks, oil stains, granular or flaky corrosion, and welding slag burns, } \\
\text { and the banded or welded steel mesh and steel skeleton must not be loosened and welded. } \\
\text { 2.Welded ioints and connecting sleeves must not be cracked. }\end{array}$}} & \multicolumn{2}{|c|}{ Appearance evaluation } & & & \\
\hline & & & & & & & & & & & \multicolumn{2}{|c|}{ Quality data evaluation } & & & \\
\hline \multicolumn{5}{|c|}{$\begin{array}{l}\text { Check the opinion : } \\
\text { Quality inspection engineer : System administrator } \\
2020 / 10 / 11\end{array}$} & \multicolumn{5}{|c|}{$\begin{array}{l}\text { Check the opinion: } \\
\text { Supervision : System administrator } \\
2020 / 10 / 11\end{array}$} & \multicolumn{6}{|c|}{$\begin{array}{l}\text { Check the opinion : } \\
\text { Supervision Engineer : System administrator } \\
2020 / 10 / 11\end{array}$} \\
\hline
\end{tabular}

Figure 7. Quality inspection form

\section{Conclusion}

This paper uses "Highway Engineering Quality Inspection and Evaluation Standard Civil Engineering" as the theoretical support to realize the automation of bridge construction quality inspection and evaluation.

In the evaluation process, the contract section, single project, subproject, and item project are used as a main line to divide the project.

In order to better adapt to on-site applications, a refined engineering division of sub-division single projects, sub-division subprojects, and sub-division item projects is proposed to improve on-site management efficiency, which has certain engineering application value.

Relying on an example of a suspension bridge project, the function of the system was verified, and very good results were achieved.

\section{References}

1. Xiang Xiaohong. Analysis on the Application of BIM in Mechanical and Electrical Installation
Engineering $[\mathrm{J}]$. Building Materials and Decoration, 2018 (22): 203-204.

2. Zhao Yue. Research and Analysis on Evaluation Method of the New Edition of "Highway Engineering Quality Inspection and Evaluation Standards" in 2017 [J]. Housing and Real Estate, 2018 (31): 27.

3. JTG F80/1-2004 Highway engineering quality inspection and evaluation standards [S]. 2004.

4. JTG F80/1-2017 Highway engineering quality inspection and evaluation standards [S]. 2017.

5. Yang Hairong, Liu Haode. Design of an integrated system for highway engineering test inspection and quality inspection evaluation [J]. Sino-foreign highway, 2009,29 (02): 263-266.

6. Shi Zhankuan, Qiao Wentao, Leng Ping. Research on the application of two-dimensional code technology based on web platform in construction management [J]. building structure, 2017,47 (S1): 1193-1196.

7. Liu Qiaoguang. On the Application of Twodimensional Code Technology in my country [J]. Telecommunications Science, 2014,30 (S1) : 243248. 